Manuscript received August 11, 2017; accepted for publication October 9, 2017; published online May 8, 2018.

1 School of Engineering, University of Limerick, Limerick V94 T9PX, Ireland (Corresponding author), e-mail: jeremy.robinson@ul.ie, (1) https://orcid.org/0000-00019469-5760

${ }^{2}$ Helmholtz Zentrum Berlin für Materialien und Energie, Hahn Meitner PI. 1, Berlin, Germany, (D) https://orcid.org/0000-00029518-0504

${ }^{3}$ School of Engineering, University of Limerick, Limerick V94 T9PX, Ireland, (1) https://orcid.org/ 0000-0002-6945-2000 (D.A.T.), (1) https://orcid.org/0000-00033116-6014 (B.M.)

${ }^{4}$ Department of Mechanical Engineering, University of Bristol, Queens Building, Bristol BS8 1TR, United Kingdom, (i) https://orcid. org/0000-0003-0174-1276

${ }^{5}$ Materials Science and Simulations, Paul Scherrer Institute, PSI Aarebrücke, Villigen $\mathrm{CH}-5232$, Switzerland
J. S. Robinson, ${ }^{1}$ R. C. Wimpory, ${ }^{2}$ D. A. Tanner, ${ }^{3}$ B. Mooney, ${ }^{3}$ C. E. Truman, ${ }^{4}$ and T. Panzner ${ }^{5}$

\section{Cold Compression of 7075 and Factors Influencing Stress Relief}

\section{Reference}

Robinson, J. S., Wimpory, R. C., Tanner, D. A., Mooney, B., Truman, C. E., and Panzner, T., "Cold Compression of 7075 and Factors Influencing Stress Relief," Materials Performance and Characterization, Vol. 7, No. 4, 2018, pp. 898-911, https://doi.org/10.1520/MPC20170130. ISSN 2379-1365

\section{ABSTRACT}

The residual stresses in heat-treated 7075 aluminum alloy blocks have been characterized using neutron diffraction, $\mathrm{X}$-ray diffraction, and incremental center-hole drilling. Specimens were quenched to induce high-magnitude residual stresses, which were then stress relieved by the controlled application of plastic deformation using a cold compression technique. The experimental variables investigated were the quench water temperature and the postquench delay. This delay is considered to influence the final residual stress magnitudes because of hardening precipitation occurring by natural aging during the period between quenching and the application of plastic deformation. Cold compression significantly lowered the residual stresses in all specimens. Neutron diffraction measurements demonstrated a benefit to applying plastic deformation as soon as possible after quenching. However, this beneficial effect was not evident when characterizing surface residual stresses using hole drilling or X-ray diffraction.

\section{Keywords}

aluminum alloy 7075 , heat treatment, residual stress, postquench delay, cold compression

\section{Introduction}

The era when aluminum alloys dominated large passenger aircraft structures now appears to be ending. Unless the cost of ownership and repairability issues surrounding the use of carbon fiber composite become untenable, aluminum alloys are set to become an 
important but secondary material in the aircraft designers' handbook. One aspect of aluminum-alloy processing that has accelerated the move to composites is the problem of shape distortion during machining operations [1,2]. These distortions are driven by residual stresses, which arise from the necessity to rapidly cool precipitation-hardened alloys as part of the heat treatment step necessary to develop high strengths $[3,4]$.

In this investigation, the residual stresses in heat-treated 7075 aluminum alloy blocks have been characterized using two neutron diffraction strain scanning instruments. Highmagnitude residual stresses arise during quenching from the solution heat treatment temperature [5]. The influence of uniaxial cold compression (or stretching) on relieving these residual stresses is an established technology [6-11]. One of the factors affecting the efficacy of the cold compression process is the time delay between quenching and cold compressing the material, although this has received almost no attention from the academic community $[12,13]$. The different cooling regimes that occur in the surface and core of a large aluminum alloy component mean that metallurgical differences exist, and thus different volumes may respond differently to subsequent aging and work-hardening processes [14]. This is especially true if the alloy is quench sensitive. In this investigation, 7075 blocks (7075 is an alloy known to be quench sensitive $[15,16]$ ) were subject to postquench delays of either 30 minutes or 240 minutes prior to a single application of approximately $1 \%$ cold compression. X-ray, neutron diffraction, and incremental center-hole drilling techniques were used to characterize the residual stresses in the blocks before and after cold compression.

\section{Experimental Details}

\section{MATERIAL, HEAT TREATMENT, AND COLD COMPRESSION}

Specimens of the Al-Zn-Mg-Cu alloy 7075 were supplied by Mettis Aerospace, Redditch, $\mathrm{UK}$, in the form of hot rolled plate. The plate was $82 \mathrm{~mm}$ thick (short transverse [ST] direction). Rectilinear blocks of the dimensions $120 \mathrm{~mm}$ (rolling direction [L], $x$ ) by $44 \mathrm{~mm}$ (long transverse [LT] direction, $y$ ) by $82 \mathrm{~mm}$ (ST, $z$ ) were cut and machined from the plate. Heat treatment included solutionizing for 2 hours at $470^{\circ} \mathrm{C}$ followed by water quenching with vigorous manual agitation. The water temperature was nominally $60^{\circ} \mathrm{C}$, but for certain specimens, cold water (temperature $<20^{\circ} \mathrm{C}$ ) was used. Each block was quenched individually with the ST direction vertical as the block entered the water. After quenching, specimens were either aged for 7 hours at $105^{\circ} \mathrm{C}$ or cold compressed after a set period known as the postquench delay and then aged, as shown in Table 1.

Blocks were cold compressed by a single application of force in the $z$ (ST) direction on a 250-tonne $(2.45 \mathrm{MN})$ hydraulic press at a crosshead speed of $20 \mathrm{~mm} / \mathrm{s}$. The amount of compression was controlled using steel stop plates of appropriate thickness. The load-bearing surfaces $(x-y$ or L-LT) were lubricated with a light oil. The coefficient of friction during cold compression, $\mu$, determined using ring compression tests was in the range 0.15 to 0.17 [17].

The microstructure of the 7075 plate in the as-quenched condition consisted of long, pancake-type grains. The grains were 50 to $100 \mu \mathrm{m}$ thick $(z$, ST) by 150 to $200 \mu \mathrm{m}$ wide $(y, \mathrm{LT})$ with a length of 500 to $1,000 \mu \mathrm{m}(x, \mathrm{~L})$. The grains did not contain an optically resolvable substructure and did not appear to have undergone any recrystallization-type events. There was no evidence of second-phase precipitation $\left(\eta-\mathrm{MgZn}_{2}\right)$, but the expected normal coarse constituent phases were present. The intragranular precipitates arising after aging (Guinier Preston zones, $\eta$ ', and $\eta$ ) were not resolvable in the optical microscope. 
TABLE 1

Details of cold compression and aging for 7075 specimen blocks.

\begin{tabular}{|c|c|c|c|c|c|}
\hline Specimen & Strain & Water & Postquench & Cold & Aging \\
\hline Code & Scanner & Temperature, ${ }^{\circ} \mathrm{C}$ & Delay, min & Compression, \% & Treatment \\
\hline A5 & POLDI/E3 & 60 & & 0 & $7 \mathrm{~h}$ at $105^{\circ} \mathrm{C}$ \\
\hline A9 (Dzero) & POLDI/E3 & 60 & & 0 & $7 \mathrm{~h}$ at $105^{\circ} \mathrm{C}$ \\
\hline $\mathrm{A} 10$ & POLDI & 60 & 30 & 1.2 to 1.6 & $7 \mathrm{~h}$ at $105^{\circ} \mathrm{C}$ \\
\hline A6 (Dzero) & POLDI & 60 & 30 & 1.5 to 1.7 & $7 \mathrm{~h}$ at $105^{\circ} \mathrm{C}$ \\
\hline A7 & POLDI & 60 & 240 & 1.1 to 1.6 & $7 \mathrm{~h}$ at $105^{\circ} \mathrm{C}$ \\
\hline A1 (Dzero) & POLDI & 60 & 240 & 1.2 to 1.6 & $7 \mathrm{~h}$ at $105^{\circ} \mathrm{C}$ \\
\hline B8 & POLDI & 20 & & 0 & Natural age \\
\hline B7 (Dzero) & POLDI & 20 & & 0 & Natural age \\
\hline
\end{tabular}

Note: POLDI $=$ Pulse-OverLap Diffractometer, Dzero $=$ strain free reference

\section{RESIDUAL STRESS CHARACTERIZATION}

\section{Neutron Diffraction}

Measurements were made following the guidelines present in recently published papers [18-20]. Neutron diffraction was performed on two neutron diffraction strain scanning instruments. The time-of-flight neutron diffractometer Pulse-OverLap DIffractometer (POLDI) located at the Swiss Spallation Neutron Source at the Paul Scherrer Institute in Villigen, Switzerland, was used to measure the residual strains. POLDI is a time-of-flight instrument, so the positions of multiple diffraction peaks with coincidental scattering vectors were measured. This permitted the use of a full diffraction pattern-type analysis [21]. The full pattern refinement leads to the determination of an average lattice parameter based on the position of all available peaks. The refinement enabled the calculation of the lattice parameter using reflections from up to five sets of interplanar spacings (mainly the $\{200\},\{400\},\{311\}$, and $\{422\}$. This was specimen and orientation dependent).

Neutron diffraction was also performed on the strain scanning instrument, E3 (Helmholtz-Zentrum Berlin, Berlin, Germany). This was used with monochromatic radiation of the approximate wavelength $1.47 \AA$. The position of the $\{311\}$ aluminum peak was determined.

A sampling-gauge volume of approximately 2 by 2 by $2 \mathrm{~mm}^{3}$ as defined by the incident beam slit width and height and the diffracted beam radial collimators was used for both instruments. The gauge volume was estimated to contain about 1,000 grains. The blocks were positioned on the instrument stage to permit measurements of strains in the three original primary working orthogonal directions. These directions were assumed to be the principal stress directions, coinciding with the direction of maximum heat flow out of the block surfaces during quenching. The measurements originated from the vertex at the center of the blocks, moving out to the faces with the directions following the primary mechanical working directions. Strain measurements were made at discrete points along each line. Fig. 1 indicates the dimensions of the block, and the dotted lines describe the neutron diffraction line scans.

Strain-free reference prisms $(15[x, \mathrm{~L}]$ by $10[y, \mathrm{LT}]$ by $\sim 82 \mathrm{~mm}[z, \mathrm{ST}])$ were extracted from the center of duplicate blocks by electrodischarge machining. Strains were measured along the long central axis (ST, $z$ direction) of these (Dzero) prisms. No systematic variation of the strain-free lattice parameter was detected in the reference prisms. Lattice spacings were converted to residual strains and stresses using the standard 
FIG. 1

Specimen geometry used for residual stress characterization after water quenching and cold compression. The as-received hot-rolled plate was $82 \mathrm{~mm}$ thick (short transverse [ST] direction, $z$ ). Specimens of the dimensions $120 \mathrm{~mm}$ (rolling direction [L], $x$ ) by $44 \mathrm{~mm}$ (long transverse [LT] direction, $y$ ) by $82 \mathrm{~mm}$ (ST) were extracted from the plate. Cold compression was applied in the ST direction. The block center is the origin of the $x, y, z$ coordinate system. Dotted arrows describe the neutron diffraction measurement line scans.

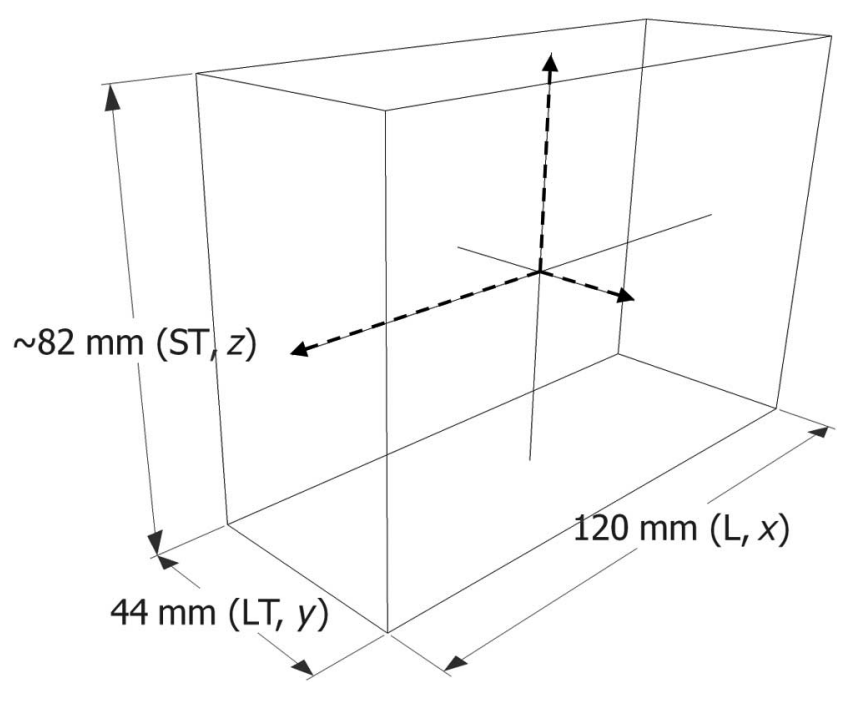

three-dimensional Hooke's law [22]. A Young's modulus (E) of $70 \mathrm{GPa}$ and a Poisson's ratio $(\nu)$ of 0.3 were used to calculate all residual stresses. These elastic constants have been found by the authors to offer the best agreement between neutron diffraction and other residual stress measurement techniques, including X-ray diffraction, incremental centerhole drilling, and deep-hole drilling for 7000-series alloys [23,24]. Multiple (repeatability) neutron diffraction measurements on the blocks and the associated stress-free specimens allowed an estimation of one standard deviation random uncertainties as $\pm 30 \mathrm{MPa}$. These uncertainties were much larger than the peak fitting errors.

\section{X-Ray Diffraction}

Residual stress measurements using a $\sin ^{2} \psi$ technique were performed on an X'Pert X-ray diffractometer (Philips, The Netherlands) using $\mathrm{Cu} \mathrm{K} \alpha$ radiation operating in the $\omega$ configuration. The measurement procedures followed were those documented in the literature and the best practice guide published by the National Physical Laboratory (NPL), Teddington, UK [25]. The position of the peak arising from diffraction from the aluminum matrix $\{422\}$ plane was measured $\left(136^{\circ}<2 \theta<139^{\circ}\right)$. Sixteen scans were performed for each stress measurement using equally spaced $\psi$ values within the range $0^{\circ} \leq \psi \leq 60^{\circ}$ (positive tilting only, $\psi=$ angle between the surface normal and the bisector of source and diffracted X-ray beam). The resulting spectra were analyzed using PC-Stress Software (Version 2.61) (Philips, The Netherlands). Peak locations were determined using a Pearson VII fitting technique. Sixteen peak positions were used to calculate the straight line $d_{\{422\}}$ (interplanar spacing) versus $\sin ^{2} \psi$ plots. The calculation of residual stress from the measured peak position was made using the established theory [26]. The elastic constants were taken from literature for the $\{422\}$ planes [27]. The irradiated area was in the form of a line $2 \mathrm{~mm}$ thick and $12 \mathrm{~mm}$ long. The penetration depth of the $\mathrm{X}$ rays was assumed to be of the order of $100 \mu \mathrm{m} \mathrm{calcu}-$ lated using reference data [26]. Calibration of the diffractometer was performed using a 
specimen with a "known" residual stress. This specimen was a piece of cold-water quenched and aged 7010 alloy that had been characterized on multiple diffractometers located in different institutions over a period of 16 years.

\section{Incremental Center-Hole Drilling}

Near-surface residual stresses were determined by ASTM E837, Standard Test Method for Determining Residual Stresses by the Hole-Drilling Strain Gauge Method, following the direction of guidelines written by the NPL $[28,29]$. Measurements were performed on blocks having strengths $>500 \mathrm{MPa}$. A Type A EA-06-125RE-120 (Vishay Measurements Group UK Ltd., Basingstoke, UK) strain gauge rosette of nominal size $1 / 8$ inch was selected to maximize the sampling gauge volume, which was evaluated at $7.4 \mathrm{~mm}^{3}$ for the $2-\mathrm{mm}$ measurement depth. The drilled-hole diameter to mean gauge diameter ratio was calculated at 0.38 from a maximum permitted 0.4 in each case, the upper level allowing increased strain sensitivity. The installation was accomplished in compliance with Measurements Group Instruction Bulletins B-129-8 and B-127-14 using M-Bond 200 adhesive [30,31]. The orbital drilling technique was implemented for each stress measurement using a Tungsten Carbide Inverted Cone 1:8-mm dental drill burr. A P-3500 Indicator employing Quarter-Bridge temperature-compensation circuitry was used to record the relaxed strains in conjunction with SB-10 Switch and Balance Unit (Vishay Measurements Group UK Ltd., Basingstoke, UK). The device had a resolution of $\pm 1 \mu \varepsilon$ and an accuracy of $\pm 0.5 \%$ of reading $\pm \mu \varepsilon$, which meets with the requirements outlined in the test standard. Residual stresses were determined by the ASTM E837 uniform calculation procedure using the specialized H-Drill computer software program (Vishay Measurements Group, Inc., Raleigh, NC) [32]. This calculation variant was considered by the authors to be the most technically appropriate for partnership with diffraction-determined results, as it provides a representative average value of the preexisting stresses in the total volume of removed material.

\section{Mechanical Testing}

The progress of artificial aging was monitored using Vickers hardness equipment calibrated with a standard test block to the requirements of ASTM E92-92, Standard Test Method for Vickers Hardness of Metallic Materials. Electrical conductivity was measured using an Autosigma 3000DL conductivity meter (Hocking, UK). Conductivity measurements were made in units of \% International Annealed Copper Standard (IACS), where $1 \%$ IACS $=0.58 \mathrm{MS}_{\mathrm{m}} \mathrm{m}^{-1}$.

\section{Results and Discussion}

\section{RESIDUAL STRESSES ARISING FROM QUENCHING INTO WATER AT $60^{\circ} \mathrm{C}$}

The residual stresses arising from quenching into water at $60^{\circ} \mathrm{C}$ (with aging for 7 hours at $105^{\circ} \mathrm{C}$ ) are shown in Fig. 2. These figures illustrate the neutron diffraction measurements made on the POLDI instrument for block A5 using A9 as the strain-free reference. In addition, surface hole-drilling measurements were made at the center of the face of the block defined by the L and ST directions. The single-value uniform stress arising from the hole-drilling measurement is presented on the appropriate figure. The data illustrate that the block contains an interior tensile stress that turns compressive as the surface is approached. This is typical of the distribution arising from immersion quenching of regularly shaped parts into water [33]. Quenching into water at $60^{\circ} \mathrm{C}$ is used commercially, as 
FIG. 2 Variation of residual stress in block A5 with position along a line from the block center towards the block surface, measured by neutron diffraction on both the POLDI and E3 instruments. Panel (a) is a line scan in the $x(L)$ direction, panel (b) is a line scan in the $y(L T)$ direction, and panel (c) is a line scan in the $z(S T)$ direction. A5 was quenched into water at $60^{\circ} \mathrm{C}$. The results from two neutron diffraction instruments are shown in addition to results from hole drilling at the center of the L-ST face in part (b).

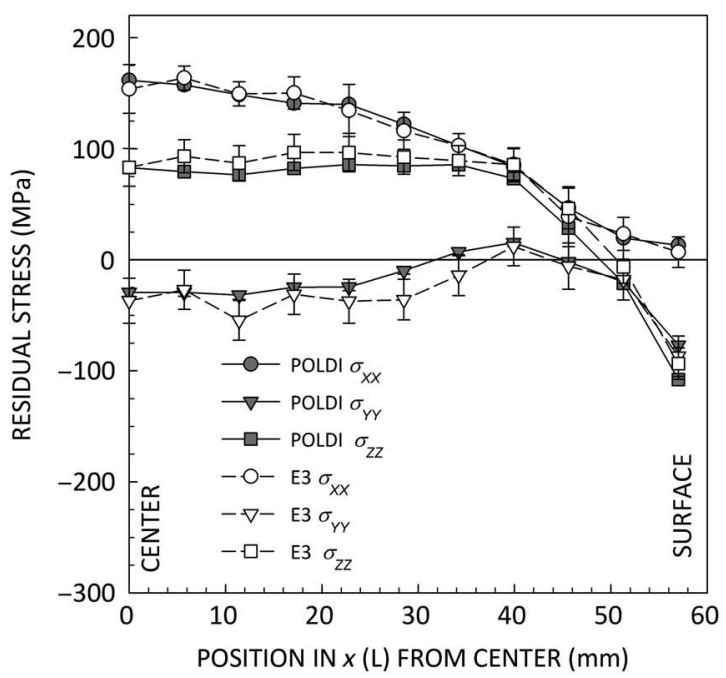

(a)

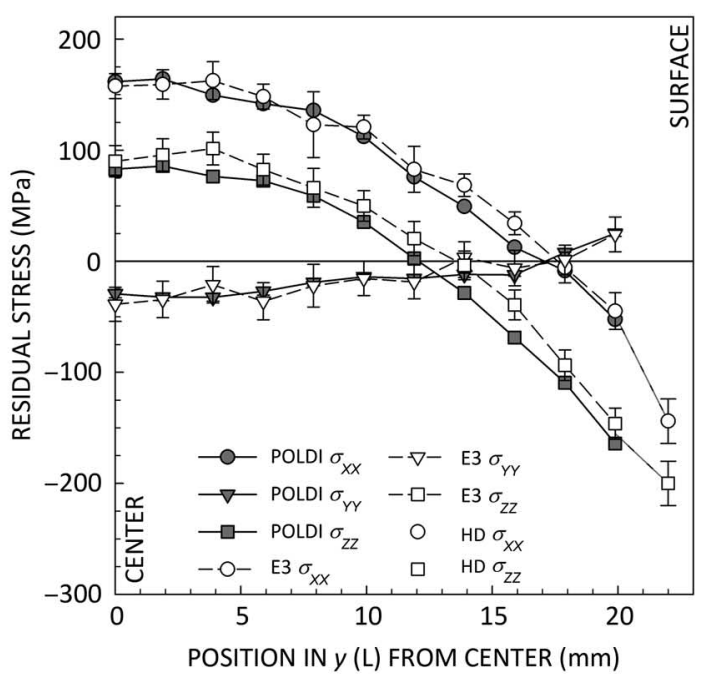

(b)

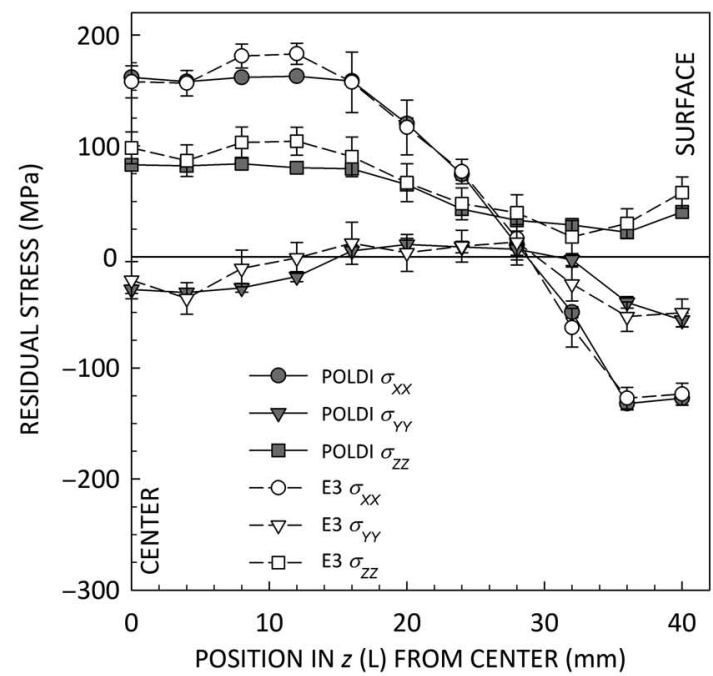

(c)

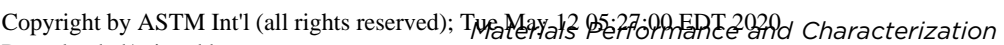


FIG. 3 Residual stresses in block A5 (quenched into water at $60^{\circ} \mathrm{C}$ ) and block B8 (quenched into cold water). Results from hole-drilling measurements at the center of the L-ST face are also shown in panel (b).

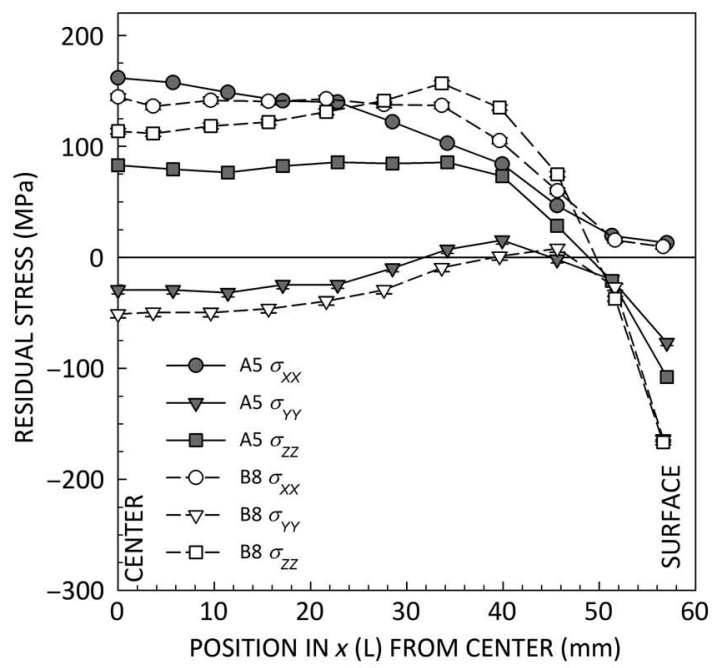

(a)

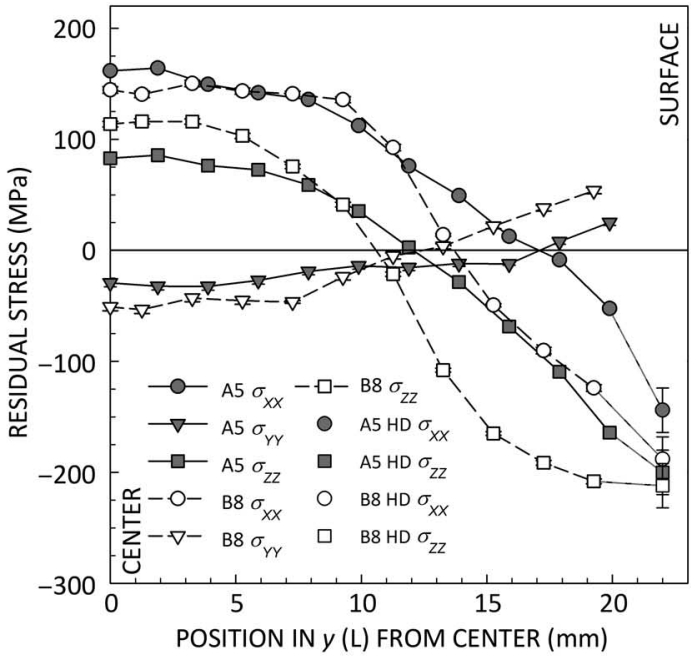

(b)

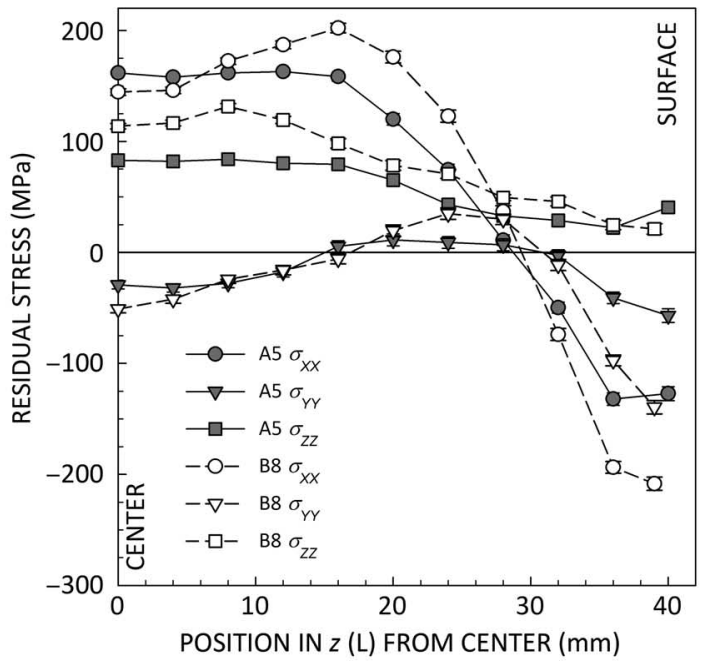

(c) 


\section{TABLE 2}

Surface X-ray diffraction (XRD) measurements corresponding to locations at the end of the neutron diffraction line scans, which are the surfaces highlighted in Fig. 3a-c for the cold water quenched (CWQ) block B8.

\begin{tabular}{lccc}
\hline Block B8 (CWQ) XRD & & Residual Stress, MPa & Peak Fit Error, MPa \\
\hline Fig. 3a & $\sigma_{y y}$ & -194 & 7 \\
& $\sigma_{z z}$ & -189 & 9 \\
Fig. 3b & $\sigma_{x x}$ & -180 & 7 \\
& $\sigma_{z z}$ & -185 & 5 \\
Fig. 3c & $\sigma_{x x}$ & -197 & 11 \\
& $\sigma_{y y}$ & -179 & 7 \\
\hline
\end{tabular}

Table 2 were in line with the neutron diffraction measurement when they were extrapolated to the specimen surface. Multiple repeat X-ray measurements were made at each location, and the values are the average of these measurements.

\section{INFLUENCE OF COLD COMPRESSION ON AS-QUENCHED RESIDUAL STRESSES}

Block $\mathrm{A} 10$ was quenched into water at $60^{\circ} \mathrm{C}$ and then cold compressed after a delay of 30 minutes. The amount of cold compression determined by measuring the block height after removal of the load was between $1.2 \%$ in the center of the block to $1.3 \%$ when measured at the long edge of the face defined by the $x(\mathrm{~L})$ and $y(\mathrm{LT})$ directions and $1.6 \%$ on the short edge. Alloys of the 7000 series naturally age at room temperature, but after 30 minutes, the changes in hardness and electrical conductivity (a common industrial measurement technique to monitor the aging process) are insignificant, as shown in Fig. 4.

The resulting residual stress distribution remaining in A10 after cold compression is shown in Fig. 5. The ordinate scale in Fig. 5a-c is the same as in Figs. 2 and 3 to facilitate comparison of the data. The application of uniaxial plastic deformation is effective at lowering all three orthogonal components of residual stress into the range $\pm 30 \mathrm{MPa}$. These observations are consistent with other investigations [37-41]. The results of the hole-drilling measurement are also included in the figure, and these observations were consistent with the

FIG. 4

Natural aging response of 7075 after quenching into water at $60^{\circ} \mathrm{C}$; Vickers hardness (using a mass of $20 \mathrm{~kg}$ ) and electrical conductivity measurements. Error bars are \pm 3 standard deviations.

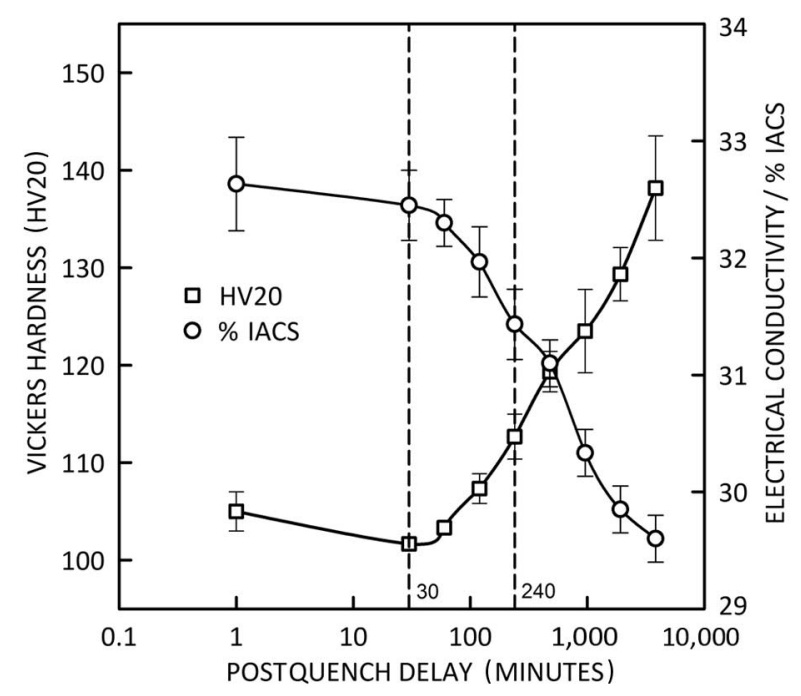


FIG. 5 Residual stresses in block $\mathrm{A} 10$ (quenched into water at $60^{\circ} \mathrm{C}$ ) and then cold compressed after a delay of 30 minutes; results from hole-drilling measurements at the center of the L-ST face are also shown in panel (b). Panel (d) is panel (a) replotted with an expanded ordinate axis and includes X-ray diffraction measurements. Errors bars arise from the peak fitting.

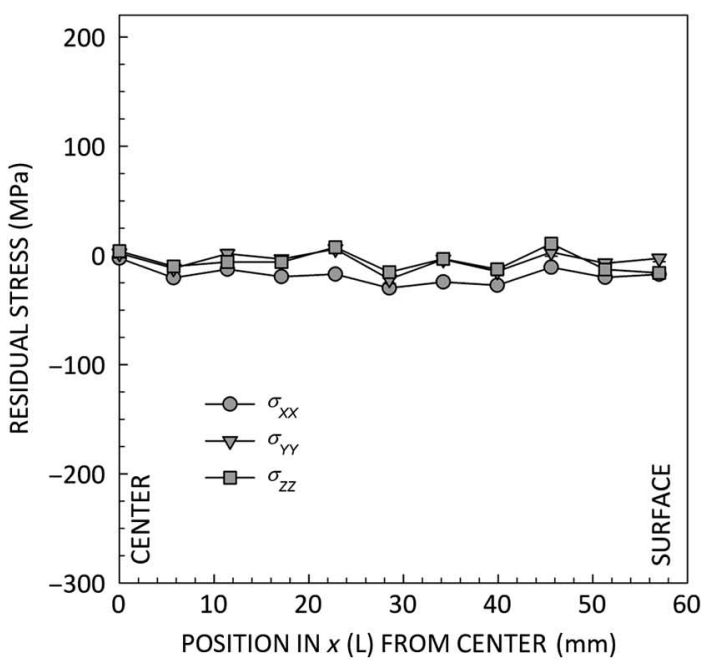

(a)

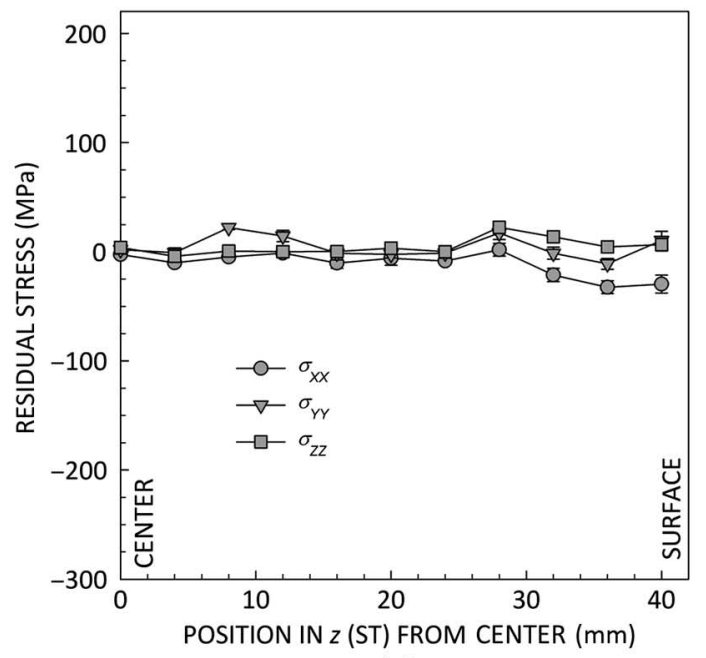

(c)

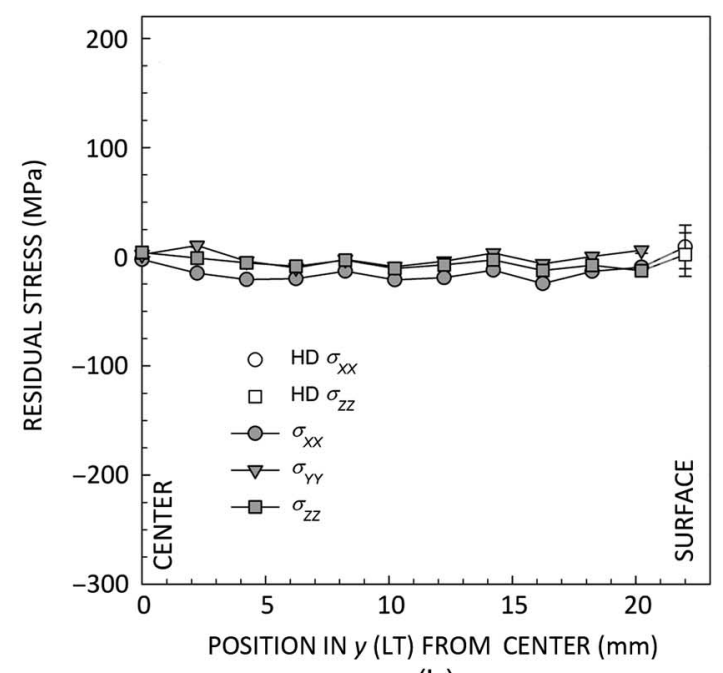

(b)

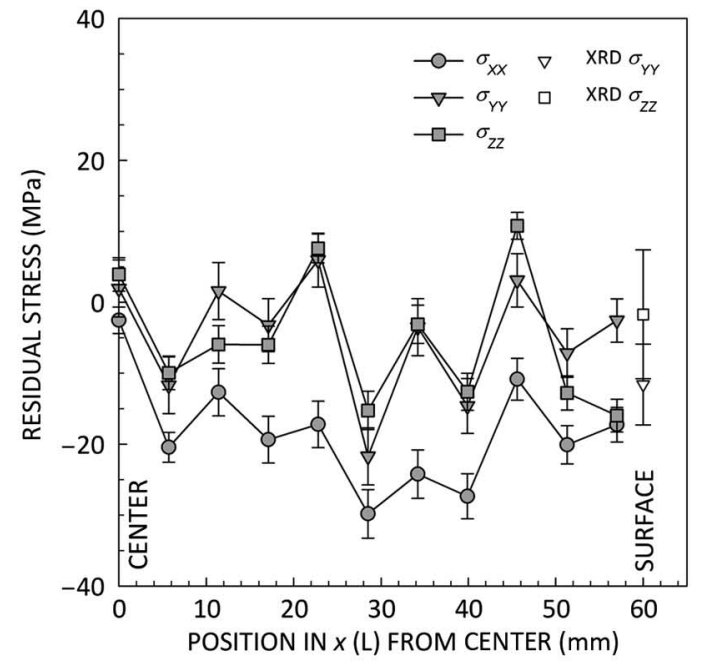

(d) 
Block A7 was treated in the same way as A10 but was allowed to naturally age for 4 hours before the application of cold compression. During these 4 hours, the electrical conductivity decreased by $4 \%$ and the indentation hardness increased by $8 \%$, both because of solute clustering and precipitation of transition phases such as Guinier Preston zones [43]. Despite being harder and therefore stronger, it was still possible to cold compress the block to almost exactly the same cold compression $(1.1 \%$ in the center of the block to $1.1 \%$ when measured at the long edge of the face defined by the $x(\mathrm{~L})$ and $y(\mathrm{LT})$ directions and $1.6 \%$ on the short edge).

The resulting residual stress distribution remaining in A7 after cold compression is shown in Fig. 6. The ordinate scale is the same as in Figs. 1, 2, and 4 to facilitate

FIG. 6 Residual stresses in block A7 quenched into water at $60^{\circ} \mathrm{C}$ and then cold compressed after a delay of 240 minutes; results from hole-drilling measurements at the center of the L-ST face are also shown in panel (b). Panel (d) is panel (a) replotted with an expanded ordinate axis and includes X-ray diffraction measurements. Errors bars arise from the peak fitting.

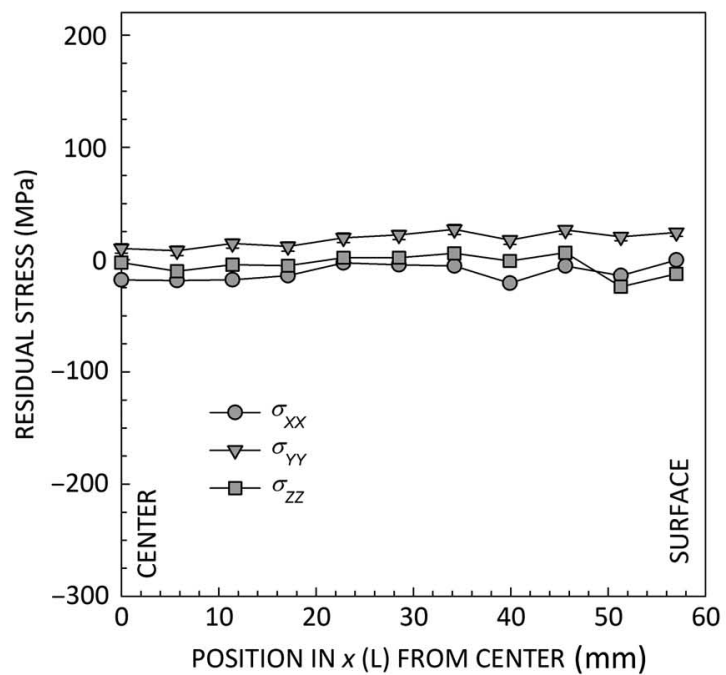

(a)

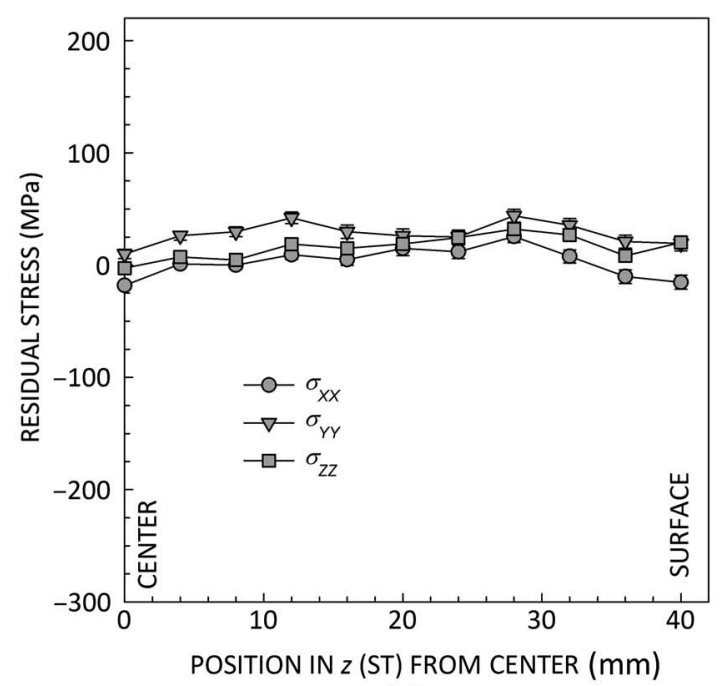

(c)

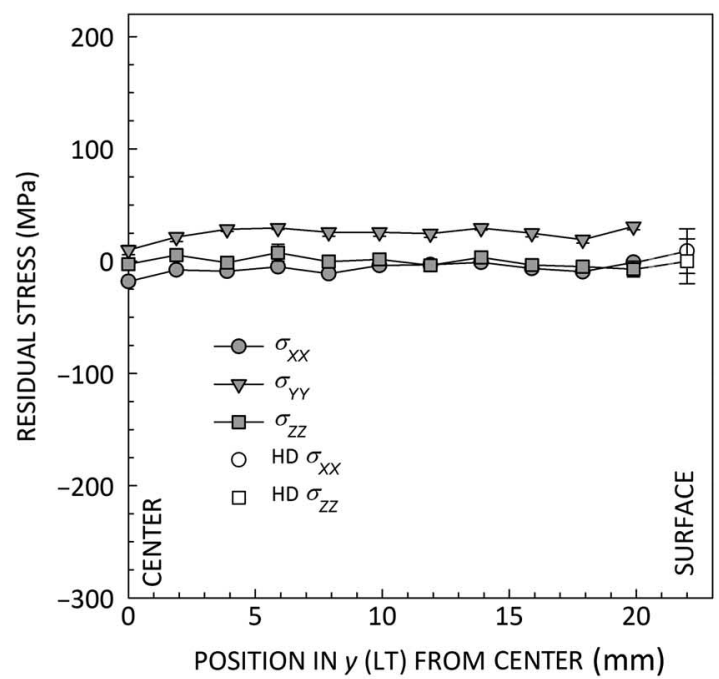

(b)

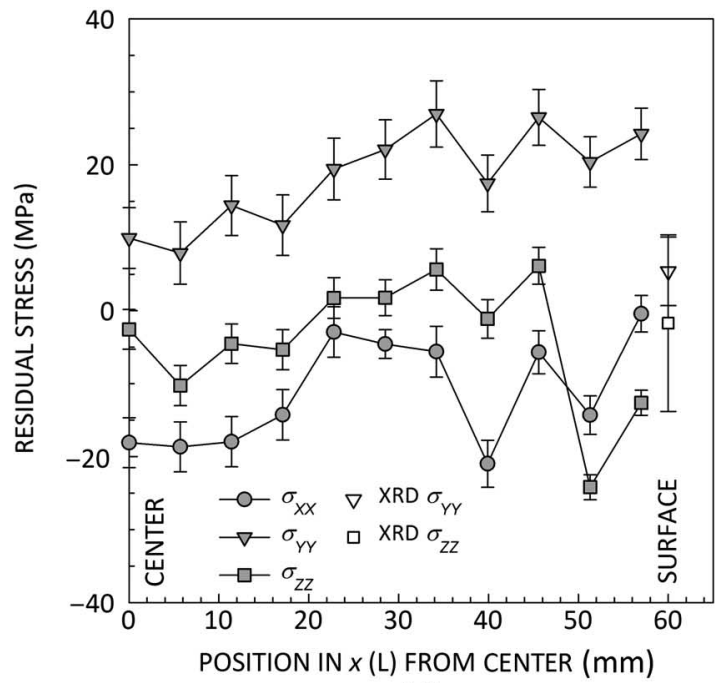

(d) 
comparison of the data. From this figure, it can be seen that for the majority of the measurement points, the range of residual stress increased $\left(\sigma_{i}^{\max }-\sigma_{j}^{\min }\right.$, where $\sigma_{i}$ and $\sigma_{j}$ can be the $\sigma_{x x}, \sigma_{y y}$, or $\sigma_{z z}$ component of residual stress). This is made more obvious when the data in Figs. $4 \mathrm{a}$ and $5 \mathrm{a}$ are replotted with the ordinate range fitted to the data, as shown in Figs. $4 \mathrm{~d}$ and $5 \mathrm{~d}$, respectively. These data suggest that allowing the material to naturally age prior to the application of cold compression is detrimental to the efficacy of the cold compression process, even when the amount of cold compression applied is the same. The effect is small, but it does reproduce observations made in a previous investigation using the aluminum alloy 7050 [44].

The postquench delay is an important processing parameter when stress relieving aluminum alloy products. The delay is currently controlled, but only to ensure the materials do not harden significantly, making the application of cold compression or stretching much more difficult or impossible. It is not known by the authors if the additional benefits of a short postquench delay are appreciated by the aerospace aluminum alloy product manufacturers. To stress relieve immediately after quenching in an industrial setting is a significant logistical undertaking. The evidence presented here is not overwhelmingly conclusive, but there have now been two investigations on 7050 and now 7075 that demonstrate the benefit. The mechanism involved that promotes more effective stress relief immediately after quenching is complex and must involve the postyield work-hardening behavior of the material. Immediately after quenching and before natural aging progresses, the response of the material is more homogenous in terms of yield and work hardening. As the material ages, through-thickness differences arising from quench sensitivity effects will give rise to differing rates of work hardening in the surface compared to the core of the material. It is thought that it is these differences that can lead to increased residual stresses after cold compression [35].

To fully identify the positive attributes of the effect, either a more sensitive residual stress measurement technique must be employed or experiments must be conducted that accentuate the differences caused by the postquench delay. For the latter, four-point bending of as-quenched beams is one possibility that will be investigated by the authors in the future. Of more interest to aluminum-alloy product manufacturers will be proof that the immediate application of cold compression reduces distortion during machining. Further experimentation in the area of mechanical dissection techniques should go some way to proving if it is worth following the recommendation of stress relieving immediately after quenching.

\section{Conclusions}

(1) The residual stress observations made by two independent neutron diffraction strain scanners instruments (POLDI and E3) on a rectilinear 7075 block quenched into water at $60^{\circ} \mathrm{C}$ are in complete agreement when bearing in mind an experimental uncertainty of $\pm 30 \mathrm{MPa}$.

(2) The through-thickness residual stress magnitudes on specimens quenched into water at $60^{\circ} \mathrm{C}$ vary from highly tensile in the core regions to highly compressive in the surface.

(3) Quenching into water at $60^{\circ} \mathrm{C}$ reduces the through-thickness residual stress magnitudes by approximately $15 \%$ compared to quenching into cold water $\left(<20^{\circ} \mathrm{C}\right)$.

(4) The application of 1.1 to $1.6 \%$ uniaxial cold compression within 30 minutes of quenching reduces the triaxial residual stresses to very low levels $\pm 30 \mathrm{MPa}$. 
(5) A postquench delay of 240 minutes permits hardening by natural aging. The alloy is $8 \%$ stronger after this time. If the material is then cold compressed by 1.1 to $1.6 \%$, the plastic deformation is not as effective in reducing the residual stresses. However, the residual stresses are still reduced to very low levels.

(6) The magnitude of the postquench delay effect is small and close to the experimental uncertainty of the neutron diffraction measurement technique, but from the number of measurements made, the results do appear to confirm that the effect is real. However, the effect of the postquench delay is not detectable using X-ray diffraction or incremental center-hole drilling.

(7) To minimize residual stresses after the application of plastic deformation, it is proposed that the stress-relieving operation be carried out as soon as possible after quenching.

\section{ACKNOWLEDGMENTS}

The authors are grateful for the neutron beam time provided by the Paul Scherrer Institute (POLDI experiment 20121538) and the Helmholtz-Zentrum Berlin (E3 experiment 14100451) and for the 7075 plate supplied by Mettis Aerospace Ltd, Redditch, UK.

\section{References}

[1] Sim, W.-M., "Challenges of Residual Stress and Part Distortion in the Civil Airframe Industry," Int. J. Microstruct. Mater. Prop., Vol. 5, Nos. 4-5, 2010, pp. 446-455, https://doi.org/10.1504/IJMMP.2010.037621

[2] Li, J.-G. and Wang, S.-Q., "Distortion Caused by Residual Stresses in Machining Aeronautical Aluminum Alloy Parts: Recent Advances," Int. J. Adv. Manuf. Technol., Vol. 89, Nos. 1-4, 2017, pp. 997-1012, https://doi.org/10.1007/s00170-016-9066-6

[3] Becker, R., Karabin, M. E., Liu, J. C., and Smelser, R. E., "Distortion and Residual Stress in Quenched Aluminum Bars,” J. Appl. Mech., Vol. 63, No. 3, 1996, pp. 699-705, https://doi.org/10.1115/1.2823352

[4] Sani, S. A., Feizabadi, J., Pourgharibshahi, M., and Hashemi, S. H., "Effect of Quenching Medium on Mechanical Properties of Alloy Al7049-T6 and Lowering of its After-Machining Warpage," Met. Sci. Heat Treat., Vol. 59, Nos. 3-4, 2017, pp. 145-149, https://doi.org/10.1007/s11041-017-0118-9

[5] Lin, G.-Y., Zhang, H., Zhu, W., Peng, D.-S., Liang, X., and Zhou, H.-Z., "Residual Stress in Quenched 7075 Aluminum Alloy Thick Plates," Trans. Nonferrous Met. Soc. China, Vol. 13, No. 3, 2003, pp. 641-644.

[6] Myer, R. T., Kilpatrick, S. A., and Backus, W. E., "Stress-Relief of Aluminium for Aircraft," Met. Prog., Vol. 3, 1959, pp. 112-115.

[7] Kleint, R. E. and Janney, F. G., "Stress Relief in Aluminum Forgings," Light Met. Age, Vol. 2, 1958, pp. 14-21.

[8] Klein, J., "Cold Reduction Technique Puts More Forgings in the Air," Precis. Met. Molding, Vol. 6, 1967, pp. 53-54.

[9] Betteridge, W., "The Relief of Internal Stresses in Aluminum Alloys by Cold Working," presented at the Symposium on Internal Stresses in Metals and Alloys, London, Oct. 15-16, 1947, Institute of Metals, London, pp. 171-177.

[10] Coules, H. E., Horne, G. C. M., Kabra, S., Colegrove, P., and Smith, D. J., “ThreeDimensional Mapping of the Residual Stress Field in a Locally Rolled Aluminium Alloy Specimen," J. Manuf. Processes, Vol. 26, 2017, pp. 240-251, https://doi.org/ 10.1016/j.jmapro.2017.02.010

[11] Pan, R., Shi, Z., Davies, C. M., Li, C., Kaye, M., and Lin, J., “An Integrated Model to Predict Residual Stress Reduction by Multiple Cold Forging Operations in Extra-Large AA7050 T-Section Panels," Proceedings of the Institution of Mechanical Engineers, Part 
B: Journal of Engineering Manufacture, SAGE Publishing, Thousand Oaks, CA, 2016, https://doi.org/10.1177/0954405416673097

[12] Lequeu, P., Lassince, P., Warner, T., and Raynaud, G. M., "Engineering for the Future: Weight Saving and Cost Reduction Initiatives," Aircr. Eng. Aerosp. Technol., Vol. 73, No. 2, 2001, pp. 147-159, https://doi.org/10.1108/00022660110386663

[13] Van Der Veen, S., Heymes, F., Boselli, J., Lequeu, P., and Lassince, P., 2006, Low internal stress Al-Zn-Cu-Mg plates, U.S. Patent 0151075A1, issued July 13, 2006.

[14] Chobaut, N., Repper, J., Pirling, T., Carron, D., and Drezet, J.-M., "Residual Stress Analysis in AA7449 As-Quenched Thick Plates Using Neutrons and Fe Modelling," presented at the 13th International Conference on Aluminum Alloys (ICAA 13), H. Weiland, A. Rollett, and W. Cassada, Eds., Pittsburgh, PA, June 3-7, 2012, John Wiley and Sons, Hoboken, NJ, pp. 285-291.

[15] Bates, C. E. and Totten, G. E., "Procedure for Quenching Media Selection to Maximize Tensile Properties and Minimize Distortion in Aluminum-Alloy Parts," Heat Treat. Met., Vol. 15, No. 4, 1988, pp. 89-98.

[16] Fink, W. L. and Willey, L. A., "Quenching of 75s-Aluminum Alloy," Trans. Am. Inst. Min. Metall. Eng., Vol. 175, 1948, pp. 414-427.

[17] Dieter, G. E., "Hot Compression Testing," Handbook of Workability and Process Design, G. E. Dieter, H. A. Kahn, and S. L. Semiatin, Eds., ASM International, Materials Park, OH, 2003, pp. 64-67.

[18] Krawitz, A. D., "Neutron Strain Measurement," Mater. Sci. Technol., Vol. 27, No. 3, 2016, pp. 589-603, https://doi.org/10.1179/1743284710Y.0000000029

[19] ISO/TS 21432:2005, Non-Destructive Testing—Standard Test Method for Determining Residual Stresses by Neutron Diffraction, International Organization for Standardization, Geneva, Switzerland, 2005, www.iso.org

[20] ISO/TTA3:2001, Polycrystalline Materials-Determination of Residual Stresses by Neutron Diffraction, International Organization for Standardization, Geneva, Switzerland, 2001, www.iso.org

[21] Pawley, G. S., "Unit-Cell Refinement from Powder Diffraction Scans," J. Appl. Crystallogr., Vol. 14, 1981, pp. 357-361, https://doi.org/10.1107/S0021889881009618

[22] Hutchings, M. T., Withers, P. J., Holden, T. M., and Lorentzen, T., Introduction to the Characterisation of Residual Stress by Neutron Diffraction, CRC Press, Boca Raton, FL, 2005, 420p.

[23] Robinson, J. S., Truman, C. E., Pirling, T., and Panzner, T., "Residual Stress Relief in the Aluminium Alloy 7075," Materials Science Forum, Vol. 905, pp. 31-39, https:// doi.org/10.4028/www.scientific.net/MSF.905.31

[24] Robinson, J. S., Hossain, S., Truman, C. E., Oliver, E. C., Hughes, D. J., and Fox, M. E., "Influence of Cold Compression on the Residual Stresses in 7449 Forgings," Adv. X-Ray Anal., Vol. 52, 2009, pp. 667-674.

[25] Fitzpatrick, M. E., Fry, A. T., Holdway, P., Kandil, F. A., Shackleton, J., and Suominen, L., "Determination of Residual Stresses by X-Ray Diffraction," Measurement Good Practice Guide No. 52, National Physical Laboratory, Teddington, UK, 2005, 77p.

[26] Cullity, B. D. and Stock, S. R., Elements of X-Ray Diffraction, Pearson, Upper Saddle River, NJ, 2001, 664p.

[27] Hauk, V. M. and Macherauch, E., "A Useful Guide for X-Ray Stress Evaluation (XSE)," Adv. X-Ray Anal., Vol. 27, 1984, pp. 81-89.

[28] ASTM E837-13a, Standard Test Method for Determining Residual Stresses by the Hole Drilling Strain Gauge Method, ASTM International, West Conshohocken, PA, 2013, www.astm.org

[29] Grant, P. V., Lord, J. D., and Whitehead, P. S., "The Measurement of Residual Stresses by the Incremental Hole-Drilling Technique," Measurement Good Practice Guide No. 53, National Physical Laboratory, Teddington, UK, 2006, 63p.

[30] Micro Measurements, "Strain Gage Installations with M-Bond 200 Adhesive," Instruction Bulletin B-127-14, Vishay Precision Group, Malvern, PA, 2005, 4p.

[31] Micro Measurements, "Surface Preparation for Strain Gage Bonding," Instruction Bulletin B-129-8, Vishay Precision Group, Malvern, PA, 2014, 7p. 
[32] Schajer, G. S., Hole-Drilling Residual Stress Calculation Program, Version 2.20, User Guide, Vishay Measurements Group, Inc., Raleigh, NC, 2001, 46p.

[33] Prime, M. B. and Hill, M. R., "Residual Stress, Stress Relief, and Inhomogeneity in Aluminum Plate," Acta Mater., Vol. 46, No. 1, 2002, pp. 77-82.

[34] Croucher, T. R. and Butler, D., "Quenching, Major Stress Source in Treated Aluminium Alloys," Heat Treat., Vol. 12, No. 10, 1980, pp. 34-37.

[35] Robinson, J. S., Tanner, D. A., and Truman, C. E., "50th Anniversary Article: The Origin and Management of Residual Stress in Heat-Treatable Aluminium Alloys," Strain, Vol. 50, No. 3, 2014, pp. 185-207, https://doi.org/10.1111/str.12091

[36] Robinson, J. S., "Residual Stress in Heat Treatable Aluminum Alloys," ASM Handbook Volume 4E: Heat Treating of Nonferrous Alloys, G. E. Totten and D. S. MacKenzie, Eds., ASM International, Materials Park, OH, 2016, pp. 198-213.

[37] Altschuler, Y., Kaatz, T., and Cina, B., "Relief of Residual Stresses in a High-Strength Aluminum Alloy by Cold Working," Mechanical Relaxation of Residual Stresses, ASTM STP993, L. Mordfin, Ed., ASTM International, West Conshohocken, PA, 1988, pp. 19-29, https://doi.org/10.1520/STP26357S

[38] Bains, T., "Residual Stress Reduction in Aluminum Die Forgings," presented at the First International Non-Ferrous Processing and Technology Conference, St. Louis, MO, March 10-12, 1997, ASM International, Materials Park, OH, pp. 221-231.

[39] Alexander, J. M., "An Analysis of the Plastic Bending of Wide Plate, and the Effect of Stretching on Transverse Residual Stresses," Proc. Inst. Mech. Eng., Vol. 173, No. 1, 2006, pp. 73-96, https://doi.org/10.1243/PIME_PROC_1959_173_018_02

[40] Koç, M., Culp, J., and Altan, T., "Prediction of Residual Stresses in Quenched Aluminum Blocks and Their Reduction through Cold Working Processes," J. Mater. Process. Technol., Vol. 174, Nos. 1-3, 2006, pp. 342-354, https://doi.org/10.1016/j.jmatprotec. 2006.02.007

[41] Zhang, Z., Yang, Y., Li, L., Chen, B., and Tian, H., "Assessment of Residual Stress of 7050-T7452 Aluminum Alloy Forging Using the Contour Method," Mater. Sci. Eng. A, Vol. 644, 2015, pp. 61-68, https://doi.org/10.1016/j.msea.2015.07.018

[42] Escobar, K., Gonzalez, B., Ortiz, J., Nguyen, P., Bowden, D., Foyos, J., Ogren, J., Lee, E. W., and Es-Said, O. S., "On the Residual Stress Control in Aluminum Alloy 7050," Materials Science Forum, Volumes 396-402, Trans Tech Publications Ltd., Zürich, Switzerland, 2002, pp. 1235-1240, https://doi.org/10.4028/www.scientific.net/MSF. 396-402.1235

[43] Martin, J. W., Precipitation Hardening, Butterworth-Heinemann, Oxford, 1998, 236p.

[44] Robinson, J. S., Tiernan, P. J., and Kelleher, J. F., "Effect of Post-Quench Delay on Stress Relieving by Cold Compression for the Aluminium Alloy 7050," Mater. Sci. Technol., Vol. 31, No. 4, 2014, pp. 409-417, https://doi.org/10.1179/1743284714Y. 0000000571 